Revista Baiana

de Saúde Pública

\title{
ADOLESCÊNCIA, GÊNERO E PROCESSO DE VULNERABILIDADE/DESFILIAÇÃO SOCIAL: COMPREENDENDO AS RELAÇÕES DE GÊNERO PARA ADOLESCENTES EM SITUAÇÃO DE RUA
}

\author{
Daniela Tavares Gontijo ${ }^{a}$ \\ Marcelo Medeiros ${ }^{b}$
}

\section{Resumo}

A efetividade de ações de promoção de saúde destinadas a adolescentes em situação de rua perpassa pela compreensão das diferentes relações de poder que se inter-relacionam no cotidiano, inclusive das relações de gênero. Neste artigo, objetivou-se descrever e analisar como se manifestam as relações de gênero para adolescentes em situação de rua. Pesquisa qualitativa do tipo social estratégica, realizada em duas instituições de assistência a adolescentes em situação de rua, na qual foram entrevistados 13 adolescentes. Os dados coletados foram submetidos ao Método de Interpretação de Sentidos, sendo possível identificar e discutir a permanência e o impacto das concepções hegemônicas em relação ao gênero no cotidiano de jovens em situação de rua, marcados pelo processo de vulnerabilidade e desfiliação social, principalmente no que se refere à dimensão do controle da sexualidade feminina e à valorização da função masculina de provedor material. Concluiu-se que as relações de gênero para adolescentes em situação de rua estão presentes e são construídas e significadas cotidianamente pelos sujeitos. Este processo de significação dos fenômenos sociais se dá dentro dos contextos sociais e históricos do qual fazem parte.

Palavras-chave: Adolescência. Gênero. Vulnerabilidade social. Juventude de rua.

\footnotetext{
a Terapeuta Ocupacional. Doutora em Ciências da Saúde (UnB). Professora Adjunta do curso de Terapia Ocupacional da Universidade Federal do Triângulo Mineiro.

${ }^{b}$ Enfermeiro. Doutor em Enfermagem (USP). Professor Associado do curso de Enfermagem da Universidade Federal de Goiás. Endereço para correspondência: Rua Monte Alverne, 246 apto 401 bloco 1, Bairro Estados Unidos, Uberaba, MG. CEP:38.015-360.daniela@to.uftm.edu.br; danielatgontijo@gmail.com.br
} 


\title{
ADOLESCENCE, GENDER AND SOCIAL DISAFILLIATION/VULNERABILITY PROCESS: \\ UNDERSTANDING THE RELATIONS OF GENDER TO HOMELESS ADOLESCENTS
}

\begin{abstract}
The effectiveness of health promotion actions to homeless adolescents entails the understanding of different power relationships that interrelate in daily life, including those of gender. The objective of this paper is to describe and analyze how gender manifests in homeless adolescents. Qualitative research of strategic social type was carried out in two institutions for homeless adolescents, where 13 adolescents were interviewed. Data collected were submitted to Meaning Interpretation Method, enabling the identification and discussion about the prevalence and impact of gender hegemonic conceptions in the routine of homeless adolescents, marked by vulnerability/disaffiliation process, mainly in relation to dimension of feminine sexuality control and to valorization of masculine function as material provider. It is assumed that gender relations are present, are built and signified for homeless adolescents in their everyday experiences. This process of social phenomena signification occur within the social and historic contexts in which they are inserted.
\end{abstract}

Key words: Adolescence. Gender. Social vulnerability. Homeless youth.

\section{INTRODUÇÃO}

O planejamento e a sistematização de ações de prevenção de doenças e promoção de saúde destinados às e aos adolescentes e jovens, que fazem das ruas seu espaço de vida, caracteriza-se como um desafio cotidiano. Este desafio perpassa pela necessidade de se apreender o sujeito em seu contexto real de vida, que se caracteriza por suas múltiplas dimensões e por um processo de construção sócio-histórica e cultural, no qual identificamos relações de poder que acabam por configurar formas de existências sociais diversas.

A existência social ${ }^{1-3}$ de indivíduos e grupos pode se configurar de forma dinâmica, com base em sua inserção no mundo do trabalho e em sua rede social de suporte. Nesta perspectiva, a participação inconstante e aleatória no mundo do trabalho e a escassez de relações significativas e que sejam fonte de suporte social representam uma situação de vulnerabilidade social. Esta situação, vivenciada por muitas famílias brasileiras, impele-as ao desenvolvimento de estratégias em busca da sobrevivência diária e, entre estas, a busca pela rua como cenário principal de vida e de trabalho pelas crianças e adolescentes.

Viver em situação de rua representa uma forma de existência social marcada pela fragilidade, em diferentes intensidades, das relações sociais estabelecidas pelos sujeitos, que pode 
Revista Baiana de Saúde Pública culminar em um processo de ruptura total, configurando a situação de desfiliação, de não pertencimento comunitário. ${ }^{4,5}$ É neste contexto de privações de ordem econômica e social que adolescentes em situação de rua desenvolvem-se e vão construindo sua história, permeada por relações de poder marcadas pela desigualdade.

Entre estas relações de poder, as relações de gênero destacam-se, uma vez que as construções sociais acerca do feminino e do masculino delineiam possibilidades e limitações nas diferentes formas de existência social.

O conceito de gênero tem sua formulação iniciada na luta das mulheres pela igualdade social e política, que tem lugar a partir da segunda metade do século XX, com o movimento feminista. Esse processo, que se inicia na análise da condição da subordinação das mulheres e passa pela fase dos estudos sobre as condições concretas de vida das mulheres, tem se configurado atualmente por uma perspectiva relacional. ${ }^{6}$ Atualmente, falar em gênero implica em considerar que as desigualdades observadas entre homens e mulheres não se explicam somente por suas características biológicas e naturais, mas basicamente pelos processos históricos que caracterizam um padrão de relações de gênero. ${ }^{7}$

A definição do conceito de gênero perpassa pela compreensão de dois aspectos. ${ }^{8}$ Inicialmente o gênero deve ser considerado como constitutivo das relações sociais, com base nas diferenças percebidas entre os sexos. O segundo aspecto relacionado à conceituação de gênero refere-se à concepção de que o gênero é uma primeira forma de significar as relações de poder, que se dão de forma assimétrica, constituindo-se como um meio de apreender o sentido e de compreender as complexas relações que caracterizam a interação humana. Este processo caracteriza o gênero como construção social e muitas vezes é utilizado para justificar ou naturalizar determinados comportamentos e atitudes sociais na vida cotidiana.

Sendo construção social, as relações de gênero não somente são diversas entre as sociedades ou em distintos momentos históricos, mas também no interior de uma mesma sociedade, quando se consideram os diferentes grupos (étnicos, religiosos, raciais, de classe, entre outros) que a constituem.

Considerando que esta concepção das relações de gênero pressupõe a percepção da inexistência de essências imutáveis e universais específicas de homens e de mulheres e a necessidade de se abarcar diferentes formas de ser e estar no mundo, ${ }^{7,9}$ este estudo tem origem na necessidade de identificação e compreensão de como o processo social de construção das relações de gênero se configura e se relaciona a um contexto de vida em situação de rua, marcado pelo processo de vulnerabilidade e desfiliação social, com base nas percepções dos sujeitos que o vivenciam. 
Assim sendo, neste artigo, objetivamos descrever e analisar como se manifestam as relações de gênero para adolescentes em situação de rua de um grande centro urbano brasileiro. Esperamos contribuir para o aprofundamento da discussão de como estas relações se manifestam em grupos de jovens em processo de vulnerabilidade/desfiliação, a fim de oferecer subsídios para o planejamento e a implantação de ações de prevenção de doenças e promoção de saúde direcionada às necessidades desta população em seus contextos reais de vida.

\section{PERCURSO METODOLÓGICO}

Pesquisa de abordagem qualitativa do tipo social estratégica. ${ }^{10} \mathrm{O}$ estudo foi realizado em duas instituições localizadas em uma capital do Brasil, as quais se caracterizam como locais que adolescentes do sexo masculino e feminino que vivem nas ruas podem frequentar, realizar a higiene pessoal, dormir e alimentar-se e ainda participar de atividades socioeducativas.

Participaram do estudo 13 adolescentes (8 do sexo masculino e 5 do sexo feminino) com idade entre 10 e 19 anos incompletos e tempo de permanência nas ruas superior a 6 meses. O número de participantes do estudo fundamentou-se nos critérios de saturação e consistência dos dados definidos para pesquisas qualitativas. ${ }^{11-15}$

O grupo das 5 meninas foi composto por adolescentes com idade média de 15,4 anos. Quatro delas informaram ter ido para as ruas, em média, aos 12 anos, devido a episódios de violência sexual, cometidos por padrasto ou tio, no âmbito familiar. Para uma das adolescentes, a ida para as ruas se deu de forma mais precoce (por volta dos 5 anos), pois representa a quarta geração de uma família que vive em situação de rua. Das 5 adolescentes, 1 (F1) tem uma filha de 10 meses e outras 2 relatam episódios de abortos; todas manifestam o desejo de ser mãe.

O grupo dos meninos foi formado por 8 adolescentes, com idade média de 15,8 anos. O início da trajetória nas ruas foi identificado em média aos 8 anos de idade, sendo a influência de amigos e parentes, a utilização de drogas e o trabalho os principais motivos. Neste grupo, dois garotos relatam serem pais e três descrevem episódios de gravidez que culminaram em aborto ou não se confirmaram.

Os dados foram coletados por meio de entrevistas individuais semiestruturadas, gravadas em meio digital e posteriormente transcritas e submetidas ao Método de Interpretação de Sentidos. ${ }^{15,16}$ Este método caracteriza-se como um processo de categorização sucessivo, no qual são identificadas as ideias centrais. Estas são agrupadas em núcleos de sentido e posteriormente em categorias temáticas. Após esse processo, os dados empíricos são articulados com o referencial teórico e os objetivos do estudo, resultando em uma síntese interpretativa. 
Revista Baiana de Saúde Pública
Este estudo é um recorte da pesquisa Adolescentes em Situação de Rua: Compreendendo os Significados da Maternidade e Paternidade em um Contexto de Vulnerabilidade e Desfiliação, ${ }^{4}$ sendo aqui apresentados os conteúdos referentes a uma das categorias temáticas que emergiram dos dados empíricos, que se refere diretamente às relações de gênero constituídas no contexto das ruas.

A pesquisa obteve aprovação do Juizado da Infância e Juventude do Estado de Goiás e do Comitê de Ética do Hospital das Clínicas da Universidade Federal de Goiás (Parecer nº. 082/ 04), sendo a participação no estudo também condicionada à assinatura do Termo de Consentimento Livre e Esclarecido pelo(a) adolescente.

\section{RESULTADOS E DISCUSSÃO}

Nas histórias dos jovens participantes de nossa pesquisa, é possível identificar as marcas do processo de vulnerabilidade intensa vivenciado por estes e suas famílias de origem. Desemprego, privação de aspectos básicos à sobrevivência, como alimentação e condições de moradia dignas, violência, falta de suporte social, preconceito, são assuntos recorrentes na fala destes jovens. Estes aspectos influenciam diretamente a capacidade e as possibilidades destas famílias de exercerem as funções de elemento socializador de suas crianças e de suporte afetivo e material. Assim, em seus discursos, os jovens trazem composições familiares complexas, nas quais a circulação de crianças mostra-se muito presente. Nesta circulação, observamos a predominância quase absoluta de figuras femininas (tia, avó, vizinha) que se responsabilizam pelo cuidado destas crianças e jovens; as figuras masculinas, neste processo, só foram referenciadas por dois jovens.

Na época identificada como de saída para as ruas, somente dois entrevistados (um garoto e uma garota) moravam com pai e mãe biológicos. Quatro dos entrevistados relatam que moravam somente com a mãe, que tinha um companheiro; três foram criados pela avó, sem muito contato com os pais; e quatro relataram ter sido "adotados". Esta adoção, com base nos relatos e nas anotações nas pastas da instituição, não se refere à atitude legal de adoção; aparentemente se refere à ampliação do núcleo familiar e à prática de circulação de crianças, enquanto estratégia de sobrevivência em contextos de extrema vulnerabilidade. ${ }^{17-19}$

Neste estudo, somente em dois casos, os/as adolescentes fazem referência à figura paterna; figuras femininas (mãe, avó) mostram-se muito mais presentes, quando nos referimos ao cuidado. É importante pontuarmos que a ausência de figuras masculinas de referência na família também pode estar relacionada à relação entre a precariedade econômica e as concepções de gênero hegemônicas, nas quais ao pai, tradicionalmente, é atribuída a função de provedor material 
dos filhos. A impossibilidade de exercer esta função, em decorrência da não inserção no mundo do trabalho, pode contribuir para o afastamento do pai da família.

A escolha pelas ruas como estratégia de sobrevivência evidencia diferenças de gênero importantes. Para as jovens, a saída para as ruas está mais relacionada, em sua maioria, a episódios de violência, especialmente sexual, no contexto familiar, conforme relata a quarta entrevistada: "[...] eu fui estuprada pelo meu tio." (M4).

Os meninos, como explicitado no trecho a seguir, atribuem a ida para as ruas mais à influência de amigos, uso de drogas, desentendimentos com padrasto e inserção no mercado de trabalho: "Eu levava suspensão na escola, comecei a sair com os amigos, comecei a usar drogas, aí foi indo, eu comecei a brigar com a minha mãe, aí acabou que eu fui pra rua." (M5).

A apropriação dos mundos público e privado por jovens em nossa sociedade recebe influências diretas das relações de gênero presentes no imaginário social. À mulher é reservado o mundo privado, o espaço doméstico, enquanto o mundo público torna-se o espaço de socialização do homem. ${ }^{20}$ Neste sentido, a rua pode ser vista como um lugar mais perigoso para as mulheres, enquanto aos garotos é estimulada a sua conquista, por exemplo, por meio das brincadeiras ou inserção precoce no mercado de trabalho. Outros estudos também trazem que a saída da jovem para as ruas é geralmente precedida por condições de violência e privações mais sérias do que para os rapazes.21,22

De uma forma geral, para os garotos, percebemos um processo paulatino de ida para as ruas, mediado por amigos ou trabalho, conforme pontuado anteriormente e relatado por um dos garotos: "[...] aí foi indo, foi indo, eu comecei a vim pra rua e ficava. Vinha pra rua e ficava dois, três dias; vinha pra rua para engraxar e ficava uma semana; foi indo, até que um dia eu vim pra rua e fiquei um mês; aí depois eu fiquei dois meses, aí eu passei..." Por outro lado, para a maioria das meninas, a trajetória para as ruas deu-se de forma mais abrupta, permeada por passagens em instituições.

Aparentemente, esta diferença de gênero no percurso até a rua está relacionada à natureza dos motivos que levam meninas e meninos para este contexto. Conforme discutido anteriormente, e também constatado por outros estudos, ${ }^{21-23}$ a saída da jovem para as ruas geralmente é precedida por condições de violência e privações mais sérias do que para os rapazes, o que resulta em um afastamento mais abrupto destas do contexto familiar.

Uma vez nas ruas, os jovens e as jovens vivenciam suas vicissitudes. Relações sustentadas pela violência, uso de substâncias ilícitas, desenvolvimento de estratégias de obtenção de comida e dinheiro, estabelecimento de grupos, uso de equipamentos sociais, estabelecimento de relações afetivas e sexuais, entre outros, caracterizam o cotidiano e são também marcadas pelas relações de gênero. 
Revista Baiana de Saúde Pública
Independente de ser mulher ou homem, o grupo apresenta-se como uma estratégia de sobrevivência nas ruas. No conjunto das falas foi possível perceber que os grupos apresentam composição mista, mas existem ações a serem desempenhadas preferencialmente pelos homens ou pelas mulheres. Neste sentido, as "correrias" ou roubos, para obtenção de dinheiro, são realizadas na maior parte pelos homens; as mulheres atuam como suporte nesta atividade, vigiando e avisando-os da chegada de policiais ou de outros fatores que representem perigo, conforme relata uma das entrevistadas: "No sinal, os meninos roubam; só que os meninos faz mais é roubar, porque tem muito homem que não gosta de dar dinheiro para menino homem só pra menina mulher; aí nós fica no sinal e os meninos vai lá pro centro, pra roubar..." (F1).

Além disso, as mulheres conseguem dinheiro pedindo aos transeuntes e em sinaleiros, pois, de acordo com os(as) entrevistados(as), as pessoas dão as coisas (dinheiro, alimentação) com mais facilidade para as mulheres do que para os homens, que são chamados a "não vagabundar" e a ir procurar um trabalho: "Porque se ela for pra rua, ela ganha as coisas mais fácil, porque é mulher, né? o homem é mais difícil; o povo começa a humilhar, mandar trabalhar. Agora mulher, não; mulher chegou ali, pediu e já era." (M3).

Essa divisão sexual das tarefas reflete as concepções de gênero hegemônicas em nossa sociedade, pois, de certa forma, observamos a manutenção do papel de provedor como pertencente ao mundo do homem. Com base nas falas dos(as) participantes do estudo e de nossas observações, podemos identificar maior aceitação e proteção social da mulher, considerada frágil, em situação de vulnerabilidade, o que se reflete na fala de maior facilidade das mulheres para "ganhar as coisas" no sinal. Esta maior aceitação pode estar relacionada à associação tradicional entre homem e trabalho, que caracteriza o trabalho como valor moral para a constituição da masculinidade.

Outro aspecto pontuado pelos atores do estudo é a questão do preconceito social, que resulta na percepção de se sentirem humilhados. Contrariamente a um estudo realizado em Nova York e Toronto, ${ }^{24}$ no qual foi constatado que as mulheres experienciavam maiores discriminações, em nosso estudo, os aspectos relacionados ao estigma de "ser menino(a) de rua", presentes tanto na fala dos meninos quanto das meninas, mostra-se mais forte em relação aos homens, o que pode estar relacionado a uma maior tolerância social, em nosso meio, em relação às mulheres, conforme discutido anteriormente.

Durante a realização das entrevistas foi possível observar como a violência, em suas diferentes manifestações, permeia toda a história destes(as) jovens, caracterizando as relações sociais na família, com parceiros(as) e nos grupos. Relatos de agressões verbais e físicas, tanto sofridas quanto realizadas, são percebidos como fatos "naturais" no dia a dia, que não são alvo de maiores reflexões espontâneas. 
Neste sentido, em contextos nos quais as condições reais de existência são precárias, a violência, muitas vezes, configura-se como a forma privilegiada de comunicação e de exercício de poder e de autodeterminação para estes sujeitos. ${ }^{25}$ Além disso, assim como percebido em outro estudo, ${ }^{26}$ a exposição direta e indireta ao crime e à violência torna as pessoas em situação de rua temerosas e conscientes de sua vulnerabilidade de serem vítimas. Neste estudo, estas percepções foram mais explicitadas pelas garotas, como ilustra a fala de uma das entrevistadas, que demonstra uma análise mais crítica em relação a esta situação: "É difícil. Difícil porque na mesma hora que você tá dormindo num lugar aqui, assim, vem um e te acorda. Igual a uma vez que eu tava dormindo na rua; já tentaram me matar, queimado; é difícil." (F3).

Por outro lado, no grupo dos meninos, percebemos que estavam orgulhosos em nos contar suas atitudes violentas, o que nos remete, mais uma vez, às relações de gênero hegemônicas em nossa sociedade, nas quais a virilidade é um componente estimulado e valorizado na constituição da identidade masculina: “Nós junta nele. Eu apanho, mas quando eu cato um tijolo também, rapaz..."

Em relação ao uso de drogas, para as garotas a influência do parceiro afetivo mostrou-se mais presente nos discursos do que para os garotos, que se referem mais ao grupo de amigos na rua. Nossos dados são semelhantes aos encontrados por outro pesquisador, ${ }^{27}$ que identificou uma associação direta entre o uso de drogas e amigos "desviantes". Este pesquisador pontua que, de forma geral, os homens são mais expostos à influência de amigos desviantes, devido a maior controle social sobre as mulheres. No entanto, uma vez que essa exposição seja possível, como é o caso das meninas em situação de rua, estas se tornam mais suscetíveis ao uso de drogas em decorrência da influência de amigos, principalmente parceiros afetivos.

Para os sujeitos de nossa pesquisa, a expectativa de futuro está muito relacionada a abandonar as drogas e sair do contexto das ruas. No entanto, mais uma vez, percebemos que as expectativas de futuro são mais estruturadas no discurso das meninas do que dos meninos. Para as jovens, a construção do futuro perpassa pela aquisição de uma casa própria, pelo estudo, pela formação em uma profissão, pela possibilidade de se manterem sozinhas, como nos relata F4: "Meu sonho é esse: trabalhar, estudar e morar sozinha. Acho que é a melhor coisa que existe no mundo."

Neste aspecto, um fato que nos chamou a atenção foi a pouca referência que estas adolescentes fazem ao desejo de formarem uma família nuclear, sendo a ênfase em relação ao futuro colocada na construção de sua autonomia financeira. Esta ênfase pode estar relacionada a dois fatores que se articulam. Inicialmente, é importante considerarmos que, para muitas destas garotas, o modelo da família nuclear não representa a referência de família; a experiência vivenciada é caracterizada pelo padrão de família monochefiada, na qual a mulher assume a 
Revista Baiana de Saúde Pública função de provedora. Por outro lado, acreditamos também que o desejo manifestado por estas adolescentes está relacionado às transformações nas relações de gênero tradicionais, marcadas pela entrada da mulher no mercado de trabalho e à maior apropriação do mundo público.

Quando analisamos os discursos dos jovens, percebemos maior dificuldade de construção de possibilidades de futuro; dois entrevistados explicitam a impossibilidade de se pensar no futuro: "[...] você passa um dia hoje vivo, vai rezando pra ficar vivo no outro também; é difícil na rua" (M4). Para os entrevistados que fazem referência ao futuro, o trabalho assume importância fundamental para a construção de outras possibilidades de vida. No entanto a referência ao trabalho é feita de forma geral, não sendo definidas opções profissionais, pois, como diz M1, "Um serviço, qualquer um" seria bom, refletindo a percepção de pouca ou nenhuma perspectiva de inserção no mundo do trabalho. Essa fragilidade em relação à inserção no mundo do trabalho, que é tradicionalmente constituinte da identidade masculina, tem influência direta nos processos de significação da vida atual e futura e contribuem para o agravamento do processo de vulnerabilidade/desfiliação social destes garotos.

Finalmente, é nas relações afetivas/sexuais estabelecidas na rua que as influências das relações de gênero mostram-se mais fortes neste contexto de extrema vulnerabilidade. Um primeiro ponto que nos chamou a atenção foi a negativa unânime entre os rapazes, quando questionados diretamente, se namoram/ficam com meninas em situação de rua. Essa negativa é justificada por eles pela falta de higiene, pela troca frequente de parceiros e pelo uso de drogas pelas meninas. Para os rapazes, a menina ideal para namorar deve ser limpa, morar com a família e não ter tido muitos namorados, refletindo os padrões tradicionais de controle da sexualidade feminina, nos quais são valorizadas a inexperiência e o recato sexual por parte das mulheres. Essa veemente negativa é contraditória a todo o restante das entrevistas, na qual nos é relatada a ocorrência dessas relações com as meninas em situação de rua, inclusive relações consideradas sérias pelos rapazes.

Essa contradição não é observada na fala das garotas, que relatam o estabelecimento de relações afetivas/sexuais com os garotos de rua e a esperança de que, juntos, possam modificar essa situação. O estabelecimento de relações de afeto, de amor e entrega sexual para as mulheres em situação de rua adquire caráter central em suas vidas, "[...] seja como forma de troca pela proteção, pelas próprias carências afetivas ou ainda, pela disponibilidade de tempo e por ser alvo de disputa pelos homens, que se constituem maioria na rua". 28:153

A troca frequente de parceiros é presente na fala dos meninos e meninas; nos discursos dos garotos estas envolvem sexo e na fala das meninas caracterizam situações de "dar uns beijinhos" ou ficar, formalizando um discurso coerente com a normatização da dupla 
moralidade sexual para homens e mulheres, na qual ao homem é estimulado o exercício da sexualidade, enquanto para a mulher é valorizado o recato sexual.

Os(as) adolescentes também se referem às relações nas quais a fidelidade é exigida como casamento. Nestas relações, a não observância da fidelidade é motivo de reações extremamente violentas do parceiro, sendo considerada justificativa para facadas e morte. Observamos que os garotos relatam com orgulho o fato de sustentarem (alimentação, roupa, droga) suas namoradas na rua; esta postura é desejada por estas, mas uma vez refletindo os padrões hegemônicos das relações de gênero em nossa sociedade nos quais o homem assume a função de provedor.

\section{CONSIDERAÇÕES FINAIS}

De uma forma geral, observamos no discurso de nossos(as) jovens a influência de conteúdos presentes no imaginário social quanto às relações de gênero consideradas tradicionais. O trabalho, a proteção da parceira, a função de provedor moral e material, comportamentos de comprovação da virilidade, percepção dissociada entre sexo e reprodução, se mostram como elementos utilizados na construção da própria masculinidade. Por outro lado, a afetividade, a reflexividade e o cuidado como características do feminino. Estes conteúdos mostram-se mais fortes quando nos referimos ao futuro, ao ideal de vida; na vida concreta, muitas vezes essas relações se relativizam, sem que isso seja racionalmente percebido e apropriado pelos jovens.

Essa relativização mostra-se mais presente no discurso das garotas, por exemplo, quando algumas relatam não gostar e não depender de garotos para obtenção de coisas na rua ou para se protegerem, que sonham em trabalhar e conseguir a própria independência financeira.

O ser homem e o ser mulher, na juventude e durante toda a vida, idealmente são construídos com base em parâmetros fixos e rígidos (caracterizados pelo binarismo de papéis, heterossexualidade e dupla moralidade no que se refere à sexualidade), naturalizados e difundidos em nossa sociedade. No entanto, no cotidiano, estes parâmetros podem não se concretizar em decorrência do processo histórico-social vivenciado por estes(as) jovens, caracterizado, muitas vezes, pela impossibilidade de exercê-los em sua completude (por exemplo, como ser pai provedor em um contexto de intensa vulnerabilidade/desfiliação?) ou pelo desejo de mudanças nas relações de gênero, conforme explicitamos anteriormente.

Assim, é importante considerarmos que as relações de gênero estão presentes e são construídas e significadas cotidianamente pelos sujeitos. Este processo de significação dos fenômenos sociais se dá dentro dos contextos sociais e históricos do qual fazem parte, não sendo possível dissociar indivíduo e sociedade. ${ }^{29}$ 
Revista Baiana de Saúde Pública
Enfim, o profissional de saúde deve estar atento à complexidade que caracteriza a atuação dos sujeitos em diferentes contextos de vida, na qual as relações de gênero representam somente uma de suas dimensões. Ao proporcionar experiências, no contexto das atividades de prevenção de doenças e promoção de saúde, que lhes favoreçam a análise crítica e transformação de sua realidade, inclusive das relações de poder que a configuram, o profissional possibilita a identificação das contradições entre o ideal e o vivido, desnaturalizando conceitos que são histórica e culturalmente construídos e possibilitando a manifestação e valorização das diversidades e pluralidades que caracterizam a existência humana.

\section{REFERÊNCIAS}

1. Castel R. Da indigência à exclusão, a desfiliação. Precariedade do trabalho e vulnerabilidade relacional. In: Lancetti A, organizador. Saúde loucura. São Paulo: Hucitec; 1994. p. 21-48.

2. Castel R. As armadilhas da exclusão social. In: Castel R, Wanderley L, Belfiore-Wanderley M. Desigualdade e a questão social. 2ª ed. São Paulo: Educ; 2004. p.17-50.

3. Castel R. As metamorfoses da questão social: uma crônica do salário. $5^{\underline{a}}$ ed. Petrópolis: Vozes; 2005.

4. Gontijo DT. Adolescentes com experiência de vida nas ruas: compreendendo os significados da maternidade e paternidade em um contexto de vulnerabilidade/desfiliação [tese]. Brasília: Universidade de Brasília; 2007.

5. Gontijo DT, Medeiros M. Crianças e adolescentes em situação de rua: contribuições para a compreensão dos processos de vulnerabilidade e desfiliação social. R. Ci. Saúde Col. 2009;14(2):467-75.

6. Pirotta KCM. Não há guarda-chuva contra o amor: estudo do comportamento reprodutivo e de seu universo simbólico entre jovens universitários [Tese]. São Paulo: Universidade de São Paulo; 2002.

7. Veloso R. Relações de gênero: notas introdutórias. Enfoques 2003 jul.;2(1). Extraído de [http://www.enfoques.ifcs.ufrj.br/index03.html], acesso em [15 de outubro de 2006].

8. Scott JW. El gênero: uma categoria útil para el análisis histórico. In: Lamas M. El gênero: la construcción cultural de la diferencia sexual. México: PUEG; 1996. p. 265-302.

9. Louro GL. Gênero, sexualidade e educação: uma perspectiva pós-estruturalista. 3르 ed. Petrópolis: Vozes; 1999. 
10. Minayo MCS. O desafio do conhecimento: pesquisa qualitativa em saúde. 9ạ ed. São Paulo: Hucitec; Rio de Janeiro: Abrasco; 2006.

11. Minayo MCS, Deslandes SF, Gomes R. Pesquisa social: teoria, método e criatividade. 25a ed. Petrópolis: Vozes; 2007.

12. Minayo MCS, Assis SG, Souza ER. Avaliação por triangulação de métodos: abordagem de programas sociais. Rio de Janeiro: Fiocruz; 2005.

13. Hesse-Biber SN, Leavy P. The practice of qualitative research. Thousand Oaks: Sage Pub; 2006.

14. Creswell JW. Qualitative inquiry \& research design: choosing among five approaches. $2^{\text {nd }}$ ed. The sage Qualitative Research Kit. Thousand Oaks: SAGE Publications; 2007.

15. Gomes R, Souza ER, Minayo MCS, Malaquias JV, Silva CFR. Organização, processamento, análise e interpretação de dados: o desafio da triangulação. In: Minayo MCS, Assis SG, Souza ER. Avaliação por triangulação de métodos: abordagem de programas sociais. Rio de Janeiro: Fiocruz; 2005. p. 185-222.

16. Gomes R. Análise e interpretação de dados de pesquisa qualitativa. In: Minayo MCS, Deslandes SF, Gomes R. Pesquisa social: teoria, método e criatividade. 25a ed. Petrópolis: Vozes; 2007. p. 79-108.

17. Carvalho MCB. A família contemporânea em debate. $2^{2}$ ed. São Paulo: EDUC/Cortez; 1997.

18. Sarti CA. A família como espelho: um espelho sobre a moral dos pobres. São Paulo: Autores Associados; 1996.

19. Fonseca C. Ser mulher, mãe e pobre. In: Del Priory M. História das mulheres no Brasil. 2aㅡ ed. São Paulo: Contexto; 1997. p. 510-53.

20. Da Matta R. A casa e a rua: espaço, cidadania, mulher e morte no Brasil. Rio de Janeiro: Rocco; 1997.

21. Abdelgalil S, Gurgel RG, Theobald S, Cuevas LE. Household and family characteristics of street children in Aracaju, Brazil. Arch. Dis. Chil. 2004;(89):817-20.

22. Santana JP. Instituições de atendimento a crianças e adolescentes em situação de rua: objetivos atribuídos por seus dirigentes e pelos jovens atendidos [Dissertação]. Porto Alegre: Universidade Federal do Rio Grande do Sul; 2003. 
Revista Baiana

de Saúde Pública
23. Tyler KA. A qualitative study of early family histories and transitions of homeless youth. J. Interp. Violence 2006;21(10):1385-93.

24. Kidd SA. Youth homelessness and social stigma. J. Youth Adolesc. 2007;36(1):291-99.

25. Galheigo SM. O social: idas e vindas de um campo de ação em terapia ocupacional. In: Pádua EMM, Magalhães LM. Terapia ocupacional: teoria e prática. São Paulo: Papirus; 2003. p. 115-144.

26. Lee BA, Schereck CJ. Danger on streets: marginality and victimization among homeless people. Am. Behavioral Sci. 2005;48(8):1055-81.

27. Svensson R. Gender differences in adolescent drug use: the impact of parental monitoring and peer deviance. Youth \& society 2003;34(3):300-29.

28. Tiene I. Mulher moradora na rua: entre vivências e políticas sociais. Campinas: Alínea; 2004.

29. Barros DD, Ghirardi MIG, Lopes RE. Social occupational therapy: a sócio-historical perspective. In: Kronenberg F, Algado SS, Pollard N. Occupational therapy withoud borders: learning from the spirit of survivors. Edinburg: Churchill Livingstone; 2006. p. 140-145.

Recebido em 12.1.2009 e aprovado em 19.1.2010. 